\title{
A TELEMEDICINA NA SAÚDE SUPLEMENTAR E A RESPONSABILIDADE CIVIL DO MÉDICO NO TRATAMENTO DE DADOS À LUZ DA LGPD
}

\author{
GUILHERME MAGALHÃES MARTINS ${ }^{1}$
}

CARLOS ANDRÉ COUTINHO TELES ${ }^{2}$

\begin{abstract}
RESUMO: Este trabalho busca compreender a natureza jurídica da responsabilidade civil do médico como agente de tratamento de dados, quando no exercício da telemedicina no âmbito privado, à luz da Lei Geral de Proteção de Dados. O debate acerca de limites e de normatização adequada da telemedicina na saúde suplementar também serão explorados na presente pesquisa. Para tanto, realizou-se pesquisa bibliográfica, documental, com análise dos materiais de forma teórica e qualitativa, sendo exploratória e, tendo sido empregada a abordagem dedutiva. Ao final, em que pese a atividade médica, em regra, ser considerada atividade meio e, por isso, demandando conduta culposa para sua responsabilização, quando sob o enfoque do tratamento de dados a responsabilidade civil deve ser aferida sob o prisma da responsabilidade civil objetiva.
\end{abstract}

Palavras-Chave: Telemedicina; Saúde Suplementar; Proteção de Dados Pessoais; Regulamentação; Responsabilidade Civil.

\footnotetext{
${ }^{1}$ Doutor e Mestre em Direito Civil pela UERJ. Promotor de Justiça no Ministério Público do Estado do Rio de Janeiro. Professor permanente do Doutorado da Universidade Federal Fluminense, Niterói-RJ, Brasil. Professor associado de Direito Civil da Faculdade Nacional de Direito da Universidade Federal do Rio de Janeiro, Rio de Janeiro-RJ, Brasil. Vice-presidente do Instituto Brasilcon. Diretor do Instituto Brasileiro de Estudos em Responsabilidade Civil - Iberc. gui_mart@terra.com.br.

${ }^{2}$ Doutorando em Direitos, Instituições e Negócios pelo Programa de Pós-graduação Stricto Senso da Universidade Federal Fluminense. Mestre em Direito pelo PPGD-da Universidade Veiga de Almeida (UVA). Especialista em Responsabilidade Civil e Direito do Consumidor pela Universidade Candido Mendes (UCAM) e em Direito e Processo do Trabalho pelo Instituto Brasileiro de Mercado de Capitais (IBMEC). carlosandreteles@id.uff.br.
} 
ABSTRACT: This work seeks to understand the legal nature of the doctor's civil liability as a data processing agent, when exercising telemedicine in the private sphere, in the light of the General Data Protection Law. The debate about limits and adequate regulation of telemedicine in supplementary health will also be explored in this research. To this end, bibliographical and documentary research was carried out, with analysis of the materials in a theoretical and qualitative way, being exploratory and, having used the deductive approach. In the end, despite the fact that medical activity, as a rule, is considered a middle activity and, therefore, demanding culpable conduct for its liability, when under the focus of data treatment, civil liability must be assessed under the prism of objective civil liability.

KEYwORDS: Telemedicine; Supplementary Health; Protection of Personal Data; Regulation; Civil Liability.

\section{INTRODUÇÃO}

A pesquisa busca discutir temas recentes na legislação brasileira, a natureza jurídica da responsabilidade civil do médico como agente de tratamento de dados, quando no exercício da telemedicina no âmbito privado, à luz da Lei Geral de Proteção de Dados (LGPD). Tanto a telemedicina quanto a responsabilidade civil do médico sob este enfoque é pouco explora, porquanto justifica-se a pesquisa. Nesta perspectiva, buscamos verificar os atos normativos do Conselho Federal de Medicina (CFM) que procuram se adaptar aos novos conceitos inseridos pelo Código de Defesa do Consumidor (CDC) e pela LGPD além da legislação correlata com a matéria investigada, tratando-se de pesquisa bibliográfica, documental, com análise dos materiais de forma teórica e qualitativa, sendo exploratória e, tendo sido empregada a abordagem dedutiva.

A hipótese que se pretende confirmar ou não nesta pesquisa é que se trata de responsabilidade civil de natureza objetiva, em que pese a relação médico paciente esteja balizada, na maioria dos tratamentos, pela responsabilidade civil de natureza subjetiva.

$\mathrm{O}$ estudo se estrutura em cinco partes. Inicia-se com a conceituação e desenvolvimento histórico da telemedicina no Brasil. No segundo capítulo, desenvolvemos a relação da telemedicina com a saúde privada no Brasil, apontando questões impactantes na relação com o consumidor ao final. No terceiro capítulo discorremos, sem a pretensão de esgotar o tema, sobre questões gerais sobre da LGPD como, por exemplo, os seus fundamentos e princípios norteadores. No item seguinte é abordado o tratamento de dados, sendo apresentado conceitos e os atores envolvidos. Por fim, o estudo aborda a responsabilidade civil do médico à luz da LGPD, momento no qual são listadas três diferentes correntes. Na conclusão é verificada da hipótese acima, apontando-se sua confirmação ou não, a partir da metodologia aplicada. 


\section{SOBRE A TELEMEDICINA}

Inicialmente, faz-se necessário registrar que "a história da telemedicina antecede o surgimento de métodos de comunicação eletrônica" (FERRER-ROCA; SOSAIUDICISSA, 1998).

Há cerca de duas décadas atrás a telemedicina foi regulamentada pelo CFM, através da Resolução $\mathrm{n}^{\mathrm{o}}$ 1.643/2002, proporcionado a realização de videoconferência entre os médicos para a discussão de casos e a troca de opiniões.

No Brasil, a telemedicina é conceituada como "o exercício da medicina mediado por tecnologias interativas para fins de assistência, pesquisa, prevenção de doenças e lesões e promoção de saúde", definição esta disposta no artigo $3^{0}$ da Lei $13.989 / 2020$.

A telemedicina, regulada pela associação de Medicina Mundial, é o exercício da medicina à distância, cujas intervenções, diagnósticos, decisões de tratamentos e recomendações estão baseadas em dados, documentos e outras informações transmitidas por meio de sistemas de telecomunicações (PEREIRA, 2020, p.440).

Necessário esclarecer que artigo $5^{\circ}$ do mesmo ato normativo, reconhece a telemedicina como equivalente ao ato médico presencial, obrigando todos os profissionais médicos a observarem de forma estrita o Código de Ética Médica.

Há ainda o Ofício do CFM nº 1756/2020 - COJUR, de 19 de março de 2020, reconhecendo procedimentos que podem ser realizados pelo médico por meio da telemedicina. Já a Portaria no 467, do Ministério da Saúde, de 20 de março de 2020, reconhece a possibilidade e a eticidade da utilização da telemedicina, em caráter de excepcionalidade e enquanto durarem as medidas de enfrentamento ao novo coronavírus.

Conclui-se, portanto, que a telemedicina é considerada uma prática ética, podendo ser realizada no Brasil nos limites do que determinam a Resolução $\mathrm{n}^{\mathrm{o}}$ $1643 / 2002$, o Ofício do CFM no $1756 / 2020$, a Portaria Ministerial 467/2020 e a Lei $13.989 / 2020$.

No Congresso Nacional, também existem projetos de lei com a finalidade de regulamentação da telemedicina cuja autoria é da Deputada Federal Adriana Ventura (NOVO-SP). A articulação é voltada para aprovar o PL 1998/2020 ou o PL 2394/2020, que ainda estão tramitando perante as comissões especializadas.

Diferentemente do que se entendia, a telemedicina não é uma ferramenta, mas, sim, um método de realização de serviços médicos, mediado por tecnologias, ratificada pelo parágrafo $1^{\circ}$ do artigo 37 do Código de Ética Médica do CFM e pelo artigo $5^{\circ}$ da Lei 13.989/2020.

Com efeito, a partir da edição da Lei $n^{0}$ 13.989/2020, o CFM reconheceu a possibilidade e a eticidade de uso da telemedicina, enquanto houver necessidade para o combate do novo coronavírus.

Deve ser observado, ainda, o que está estabelecido na Resolução no CFM 1.643/2002, cuja redação permanece em vigor. Esse novo entendimento do CFM dispõe que a telemedicina poderá ser utilizada nos seguintes moldes: (i) teleorientação, autorizando aos médicos realizarem mesmo a distância a orientação 
e o encaminhamento de pacientes em isolamento; (ii) telemonitoramento, autorizando que, mediante a supervisão e orientação médicas, sejam os pacientes enfermos monitorados à distância; (iii) teleinterconsulta, autorizando a troca de informações e opiniões exclusivamente entre médicos, para auxílio em diagnósticos ou nas terapias empregadas.

Na telemedicina, os dados dos pacientes são considerados como pessoais, conforme Resolução CFM no 1.643/2002, devendo haver a necessária confidencialidade e privacidade no trato destas informações, o que é corroborado pelo Código de Ética Médica em seus artigos, 85, 88, 89 e 90, todos relacionados ao prontuário médico.

Por derradeiro cumpre destacar, conquanto não se trate de legislação específica, tanto o CDC (Lei no 8.078/1990), o Marco Civil da Internet (Lei no 12.965/2014) como a LGPD instituída pela Lei $\mathrm{n}^{-}$13.709/2018, são os principais instrumentos normativos, com repercussão direta sobre a telemedicina no Brasil. Já as principais autoridades regulatórias são o Ministério da Saúde, a Agência Nacional de Vigilância Sanitária (Anvisa), a Agência Nacional de Saúde Suplementar (ANS) e o CFM.

De maneira geral, inclusive porque não será objeto de análise, faz-se necessário apontar que o Marco Civil da Internet estabeleceu princípios, garantias, direitos e deveres para o uso da internet no Brasil e, também, determinou as diretrizes para atuação da União, dos Estados, do Distrito Federal e dos Municípios em relação àquela matéria. Não contemplou, entretanto, importantes aspectos relativos aos dados pessoais, ensejando o advento da LGPD, legislação esta que será analisada em consonância com o instituto da telemedicina, todos à luz do Código de Defesa do Consumidor.

Conclui-se este capítulo conceituando restritivamente telemedicina como um ato médico não-presencial mediado por tecnologias na relação do paciente com o médico, na saúde pública ou privada.

\section{A TELEMEDiCiNA NA SAÚDE SUPLEMENTAR}

Nos termos do artigo 196 da Constituição Federal, o sistema de saúde nacional foi instituído para assegurar o acesso universal, integral e gratuito a todos os cidadãos residentes no Brasil.

O artigo 197 da Carta Magna considera de "relevância pública as ações e serviços de saúde, (...) devendo sua execução ser feita diretamente ou através de terceiros e, também, por pessoa física ou jurídica de direito privado". Esse mesmo artigo define que compete ao Poder Público a "regulamentação, fiscalização e controle" da execução dos serviços de saúde prestados, a despeito da natureza jurídica do prestador.

De maneira complementar, a assistência à saúde é livre à iniciativa privada, tendo sua abrangência estabelecida na forma do parágrafo 1o do artigo 199 da Constituição cidadã, vejamos: 
As instituições privadas poderão participar de forma complementar do SUS, segundo diretrizes deste, mediante contrato de direito público ou convênio, tendo preferência as entidades filantrópicas e as sem fins lucrativos.

De acordo com dados retirados do sítio eletrônico da ANS $^{3}$ a Saúde Suplementar ${ }^{4}$ assiste a mais de 47 milhões de beneficiários no Brasil. Trata-se de um sistema de saúde com caraterísticas próprias e marco regulatório disposto na Lei $\mathrm{n}^{\mathrm{o}}$ 9.656/1998. Os benefícios auferidos com o desenvolvimento das tecnologias de informação e comunicação (TIC), da mesma forma, são aplicáveis à saúde suplementar.

Importante consignar que em razão das peculiaridades da legislação que rege o setor, as operadoras de planos de saúde são obrigadas a atender uma gama de procedimentos incluídos no Rol de Procedimentos e Eventos em Saúde da ANS (NUNES JUNIOR; DALLARI, 2010, p. 68). Ressalta-se que a natureza exemplificativa ou taxativa do referido rol, com um enfoque de abrangência com previsão ou não da telemedicina nesta lista de procedimentos que poder-se-ia incidir nesta temática, em que pese a imensa discussão doutrinária e jurisprudencial, não será analisada nesta pesquisa.

Com isso a relação presencial médico-paciente deve ser a regra não só na Saúde Suplementar, mas em todo Sistema Único de Saúde (SUS), sem embargo da possibilidade de se disponibilizarem recursos da telemedicina tanto no setor público como no privado (RESENDE, 2010).

Olhando para o setor privado, de fato é o objeto deste ensaio, os diversos serviços prestados no âmbito da telemedicina são plenamente aplicáveis à Saúde Suplementar. Destarte, os recursos de TIC jamais devem ser ofertados para substituir o atendimento presencial, médico-paciente, sob pena de ferir de morte o tão caro princípio da humanização. Com isso os recursos de TIC devem ser opção no aprimoramento da assistência, também no contexto da Saúde Suplementar.

Tendo em vista que as empresas buscam o lucro, e a literatura (COSTA, et al, 2020, p. 77) observa que a atenção médica por telemedicina é mais barata que o modo presencial, conclui-se que esta técnica será cada vez mais empregada pelas operadoras de saúde suplementar em seu atuar para buscar maiores cifras de lucros em sua atividade econômica, o que importa na verificação do atendimento essencial nesta relação também à luz do direito do consumidor, ou seja, se o serviço estará sendo devidamente prestado e se os dados pessoais obtidos por meio deste uso da tecnologia na medicina não será utilizado para fins indevidos.

\footnotetext{
${ }^{3}$ https://www.ans.gov.br/perfil-do-setor/dados-gerais. Acesso em 16 jan 2021.

${ }^{4}$ Para melhor compreender as críticas sobre tutela coletiva dos direitos no âmbito as Saúde Suplementar, ver: TOSTES, E. C. M.; ALVISI, E.; Martins, Plínio Lacerda. Saúde suplementar considerações e críticas sobre a regulação da ANS e a tutela coletiva dos direitos. In: Kátia Junqueira. (Org.). Repensando a regulação no Brasil novas visões e propostas. 1ed.Rio de Janeiro: Synergia Editora, 2019, v. 1, p. 193-317.
} 
Para além destas questões significativas na relação do consumidor com o plano de saúde, também importa a verificação do impacto no preço e reajuste do plano de saúde, tendo em vista que a redução de custos relativos à utilização da telemedicina deve vir junto com a redução do preço da mensalidade dos planos de saúde pagos pelos consumidores, como se infere da conclusão de Tostes (2019, p. 134).

Esta pesquisa busca a análise dos reflexos da utilização da telemedicina na relação do fornecedor com o consumidor, desta forma, os impactos desta questão serão sob a esfera de particulares, sem óbice a premissas aplicáveis também à relação pública.

A nota técnica n. 6 de 2020 da ANS determinou que os planos de saúde devem cobrir as teleconsultas, a partir da autorização legal da telemedicina. Com o aparato normativo em vigor, consultando os dados disponíveis na associação brasileira de planos de saúde ${ }^{5}$, observa-se que as Operadoras de Saúde Suplementar já entendiam este fenômeno como algo rotineiro e inexorável, estando, pois, utilizando rotineiramente, desde antes da autorização legal, a telemedicina no seu atuar; portanto, relevante se faz a análise dos riscos que esta utilização pode representar na vida das pessoas, com o fim de precaução ou prevenção nesta situação tendente a se perpetuar na sociedade brasileira ${ }^{6}$.

\section{SOBRE A LEI GERAL DE PROTEÇÃO DE DADOS}

A Lei no 13.709/2018 (LGPD), publicada em 14 de agosto de 2018, com vigência a partir de agosto de 2020, tem como o objetivo de regular as atividades de tratamento de dados pessoais em todo o território brasileiro. A LGPD se aplica a qualquer pessoa, natural ou jurídica, de direito público ou privado, que realize o tratamento de dados pessoais.

A LGPD se restringe a regular o tratamento de dados pessoais: (i) de pessoas naturais (artigo 5\%, I), de maneira que deixa de criar alguma proteção adicional aos dados de pessoas jurídicas, tampouco de pessoas falecidas; (ii) realizados no território brasileiro ou no exterior, se os dados pessoais forem coletados no Brasil, se eles se relacionarem a indivíduos localizados no território brasileiro ou se o tratamento ver por objetivo a oferta de produtos e/ou serviços o público brasileiro $\left(\operatorname{artigo} 3^{\circ}\right)$.

Estão expressamente excluídos do âmbito de aplicação da norma as hipóteses de tratamentos listadas no artigo $4^{\circ}$. Faz-se necessário destacar a grande abrangência dada ao conceito de tratamento de dados, que considera irrelevante o meio e/ou forma de tratamento dos dados, contemplando uma grande gama de atividades (coleta, produção, recepção, classificação, utilização, acesso, reprodução, transmissão, distribuição, processamento, arquivamento, armazenamento, eliminação, avaliação ou controle da informação, modificação, comunicação,

5 Disponível em: https://www.abramge.com.br/portal/index.php/pt-BR/abramge-na-midia/985apesar-de-criticas-telemedicina-ja-e-realidade-no-pais-e-deve-se-expandir. Acesso em 16 jan 2021.

${ }^{6}$ Disponível em: https://gente.globo.com/a-nova-realidade-da-telemedicina/. Acesso em 16 jan 2021. 
transferência, difusão ou extração), e alcançando tanto meios digitais como não digitais.

Os fundamentos da LGPD estão previstos no artigo $2^{\circ}$, cuja disposição remetem a comandos constitucionais que estão diretamente envolvidos ao tratamento de dados pessoais. Tem-se que esses fundamentos são desdobrados em princípios (finalidade, adequação, necessidade, livre acesso aos dados por parte dos titulares, qualidade dos dados, transparência e não discriminação) no artigo $6^{\circ}$ da LGPD.

Com efeito, esses princípios devem ser observados como diretrizes quando do tratamento de dados pessoais e, consequentemente, na interpretação da LGPD.

A LGPD, ao tratar de direitos, obrigações, responsabilidades e atribuições na proteção de dados pessoais, menciona os seguintes atores: (i) titular - pessoa natural a quem se referem os dados pessoais que são objeto de tratamento; (ii) agentes de tratamento - o controlador e o operador; (iii) controlador - pessoa natural ou jurídica, de direito público ou privado, a quem competem as decisões referentes ao tratamento de dados pessoais; (iv) operador - pessoa natural ou jurídica, de direito público ou privado, que realiza o tratamento de dados pessoais em nome do controlador; (v) encarregado - pessoa indicada pelo controlador e operador para atuar como canal de comunicação entre o controlador, os titulares dos dados e a Autoridade Nacional de Proteção de Dados (ANPD); (vi) órgão de pesquisa - órgão ou entidade da administração pública direta ou indireta ou pessoa jurídica de direito privado sem fins lucrativos legalmente constituída sob as leis brasileiras, com sede e foro no País, que inclua em sua missão institucional ou em seu objetivo social ou estatutário a pesquisa básica ou aplicada de caráter histórico, científico, tecnológico ou estatístico; (vii) autoridade nacional - órgão da administração pública responsável por zelar, implementar e fiscalizar o cumprimento desta Lei em todo o território nacional.

\section{O TRATAMENTO DE DADOS NA LGPD}

A Lei no 13.709, de 14 de agosto de 2018, mais conhecida como a Lei Geral de LGPD, trata-se de um marco legal de importância ímpar no Direito Brasileiro, com definições relevantes sobre o tema, disciplina de controle e tratamento e direitos dos titulares, que entrou em vigor em agosto de 2020.

No que diz respeito aos dados pessoais a regra geral veda o seu tratamento sem o expresso consentimento do titular ou de seu responsável legal, no caso de incapaz (artigo $7^{\circ}$, I, artigo 11, I e artigo 14). A LGPD disciplinou com rigor a formalização do consentimento para, ao que parece, evitar erro e vício da manifestação de vontade (artigo $8^{\circ}$ ), principalmente no caso de menores de idade (artigo $14, \S 1^{\circ}$ ).

Os direitos dos titulares de dados pessoais não apenas foram reconhecidos, mas, sobretudo, assegurados: (i) pela previsão de restrições no tratamento de dados pessoais e de imposição aos agentes no tratamento de dados pessoais de requisitos de segurança, acesso e controle; b) pela criação de uma estrutura de governança e accountability com definição das responsabilidades e obrigações de empresas, órgãos e entidades públicas e autoridades regulatórias quanto à transparência, ao 
monitoramento, à prestação de contas, gestão de risco e garantia dos direitos dos titulares de dados pessoais.

O artigo 5ㅜ, I da LGPD considera dado pessoal a "informação relacionada a pessoa natural identificada ou identificável”. Destarte, para ser relevante à privacidade, a informação precisa ser pessoal, nominativa, ou seja, ela deve ser coletada de forma individual e não anônima. Com isso, o titular dessa informação deve ser identificado, ou ao menos identificável, porquanto os dados não personalizados, seja pela agregação em grupos ou categorias, ou, quando individualizados, pelo anonimato, destinados exclusivamente para fins estatísticos, não afetam a esfera de intimidade.

A LGPD (artigo 5, II) conceitua dado pessoal sensível (o que neste ensaio será tratado no plural, como dados sensíveis) como dado pessoal sobre origem racial ou étnica, convicção religiosa, opinião política, filiação a sindicato ou a organização de caráter religioso, filosófico ou político, dado referente à saúde ou à vida sexual, dado genético ou biométrico, quando vinculado a uma pessoa natural.

Em relação à telemedicina, a necessidade de tratamento de grandes volumes de dados sensíveis (dados cadastrais de pacientes, histórico de doenças, solicitações e resultados de exames, hipóteses diagnósticas, plano terapêutico, evolução clínica e pareceres, prontuários dentre outros) faz com que a LGPD seja objeto não só de aprofundamento no estudo, sobretudo de observância estrita pelas operadoras e prestadores de serviços médicos.

Esses dados pessoais sensíveis têm uma esfera de proteção alargada, confirmando a preocupação do legislador, o que é cotejado por Luz e Loureiro (2018), que chamam a atenção para os desafios da sociedade moderna na proteção de dados no compartilhamento de informações dentro da sociedade de informação, principalmente no que tange à relação de confiabilidade e alienação do titular de dados em relação aos dados e ao tratamento destes dados. (COLUSSI; DOS SANTOS, 2018).

Nesse contexto, relevantes os ensinamentos do Professor Guilherme Magalhães Martins (2019, p. 67) sobre a expressão sociedade da informação:

A expressão sociedade da informação surgiu na Europa, na conferência internacional de 1980, onde a Comunidade Econômica Europeia reuniu estudiosos para avaliar o futuro de uma nova sociedade assim denominada, tendo em vista a regulamentação da liberdade de circulação de serviços e medidas para a implementação de acesso aos bens e serviços por parte dos Estados membros. Foi então utilizada pela primeira vez a expressão TIC Tecnologias da Informação e Comunicação.

Com efeito, todo o volume de informação coletado é necessário, entre outras coisas, para operacionalizar a personalização dos tratamentos e fomentar 
programas de medicina preventiva, além de alimentar sistemas de monitoramento de pacientes e outras tecnologias de apoio ao profissional de saúde.

Registre-se que o paciente tem assegurado o sigilo das informações contidas no prontuário, pois o médico não pode, sem o consentimento do paciente, revelar o conteúdo do prontuário ou da ficha médica, direito este assegurado pelo artigo $1^{\mathrm{o}}$ da Resolução do CFM no 1.605 de 15 de setembro de 2000 e no artigo 85 do Código de Ética Médica. Enquanto que no âmbito de pesquisa clínica, tem seus direitos resguardados por normativas éticas do Conselho Nacional de Saúde, órgão vinculado ao Ministério da Saúde, em especial a Resolução № 466 de 15 de dezembro de 2012 e Resolução no 510 de 7 de abril de 2016.

No que diz respeito aos requisitos para tratamento de dados sensíveis, a LGPD (BRASIL, 2018) apresenta as seguintes exigências: (i) consentimento do titular ou obrigação legal; (ii) necessidade para formulação de políticas públicas; (iii) realização de estudos por órgão de pesquisa; (iv) exercício regular de direitos em processos; (v) proteção da vida ou da incolumidade física; (vi) tutela da saúde por profissionais ou serviços de saúde; (vii) garantia de prevenção à fraude e à segurança do titular.

Esse tratamento de dados é realizado por agentes sendo classificados como agentes de tratamento de dados o operador e o controlador (artigo $5^{\circ}$, IX). O agente de tratamento é responsável pela segurança e pela qualidade dos dados captados o que decorre do Princípio da Segurança dos Dados (artigo 6o, V) e Princípio da Qualidade de Dados (artigo 6º, VII), devendo prestar contas destas obrigações.

Não menos importante é a necessidade estrita de os agentes de tratamento observarem o princípio da boa-fé e da confiança, sendo o primeiro expressamente previsto no artigo $6^{\circ}$, caput na LGPD.

\section{A RESPONSABILIDADE CIVIL DO MÉDICO COMO AGENTE DE TRATAMENTO DE DADOS PESSOAIS}

Considerando as consultas médicas realizadas por meio da técnica da telemedicina, fica claro que, o médico, utilizará o sistema de informática como ferramenta de trabalho, tendo à sua disposição, ferramentas úteis para o tratamento e formatação dos dados fornecidos por seus pacientes. A hipótese que se coloca é no sentido de qual a natureza da responsabilidade civil do médico quando realiza o tratamento de dados do paciente violando os direitos fundamentais de liberdade, de privacidade e/ou do livre desenvolvimento da personalidade da pessoa natural.

Antes de se debater, cumpre-nos informar que a natureza da responsabilidade civil no âmbito da LGPD é tema controvertido. Uma primeira corrente, apresentada por Danilo Doneda e Laura Mendes (2018, p. 555) defende que a atividade de tratamento de dados é dotada de um risco intrínseco, na medida em que há uma potencialidade danosa considerável em caso de violação desses direitos, que se caracterizam por sua natureza de direito fundamental e personalíssimo.

Constatam os autores que a LGPD tem como um dos seus principais fundamentos a minimização dos riscos de dano. Em apertada síntese, a partir 
dessas considerações sobre a finalidade da lei e dos princípios por ela adotados os autores sustentam que o legislador optou por um regime de responsabilidade objetiva, vinculando o exercício da atividade de tratamento de dados pessoais a um risco inerente, potencialmente causador de danos a seus titulares.

Indo de encontro à primeira corrente, Gisela Sampaio e Rose Meireles (2019, p. 231), defendem que a LGPD adotou a teoria subjetiva da responsabilidade civil e por isso deve haver a prova da conduta culposa do agente de tratamento na ocasião do dano, fundada (i) na omissão na adoção de medidas de segurança para o tratamento adequado dos dados, quando não fornecer a segurança que o titular dele pode esperar; (ii) no descumprimento das obrigações impostas na lei, em violação à legislação de proteção de dados pessoais ou quando deixar de observar a legislação. Em suma, sustentam as autoras que a LGPD adota a teoria subjetiva da responsabilidade civil, baseada em duas questões postas pelo legislador: (i) no artigo 42, quando o legislador faz menção a medidas de segurança; (ii) no artigo 43, II, quando o legislador estabelece excludente de ilicitude referente ao cumprimento das normas da LGPD.

Uma terceira corrente, capitaneada por Maria Celina Bodin de Moraes e João Quinelato de Queiroz (2019) sustenta que a LGPD adota a chamada teoria ativa ou proativa da responsabilidade civil. De acordo com os autores, esta teoria implica na necessidade de observar a responsabilidade civil a partir de um ponto de vista positivo, sustentado pela necessidade da adoção de posturas pelos agentes de tratamento de dados que tutelem a prevenção de danos e, com isso, a obrigação de indenizar seria medida excepcional a ser tomada.

Maria Celina Bodin de Moraes e João Quinelato (2019, p. 118) destacam que

(...) a proteção da intimidade por vias da mera não interferência na esfera individual cede espaço à tutela positiva e proativa, isto é, que garanta ao titular o conhecimento pleno das formas de tratamento, finalidade e destino de seus dados.

Seguem defendendo que os dados pessoais, por constituírem conteúdo do direito à privacidade, impõem que "a coleta e o tratamento de dados pessoais deve ser precedida de medidas rigorosas e eficazes de proteção, especialmente em relação aos dados sensíveis, núcleo duro da dignidade humana" (MORAES; QUEIROS, 2019, p. 119).

Por fim, sustentam que a responsabilidade proativa está prevista no artigo $6^{\circ}$, $X$, da LGPD, que reconhece o princípio da responsabilização e prestação de contas impondo aos agentes de tratamento de dados pessoais a "demonstração, pelo agente, da adoção de medidas eficazes e capazes de comprovar a observância e o cumprimento das normas de proteção de dados pessoais e, inclusive, da eficácia dessas medidas".

Filiamo-nos a corrente que sustenta que a responsabilidade civil goza de natureza objetiva, o que se extrai da interpretação da redação do artigo 42 da LGPD, 
haja vista a vinculação da responsabilidade do agente ao risco da sua atividade, remetendo aos ditames do artigo 927, § único do Código Civil.

Faz-se necessário pontuar que o diploma normativo da LGPD não deve ser aplicado de forma indiscriminada em todos os casos envolvendo a responsabilidade civil, podendo, dependendo da relação jurídica subjacente, ceder espaço ao Código de Defesa do Consumidor, conforme disposto no artigo 45 da LGPD.

Assim, não há dúvidas que a operadora de serviços de saúde, bem como o plano de saúde ofertando agindo como fornecedor de serviços por meio da técnica da telemedicina responderão sob a égide do Código de Defesa do Consumidor uma vez configurado o dano em decorrência violação à legislação de proteção de dados pessoais.

Isso porque os serviços prestados devem levar em consideração a teoria do risco do empreendimento. Sobre o tema as lições de Martins, Ramada e Franco (2020):

\begin{abstract}
Destaca-se por fim, a teoria do risco do empreendimento como orientação para que a responsabilidade civil do fornecedor se dê de forma objetiva. O risco proveniente da atividade do fornecedor é suscetível de previsão antecipada, necessário para a proteção do consumidor vulnerável, o que também se aplica aos chamados riscos do desenvolvimento, isto é, aqueles que não podem ser cientificamente conhecidos no momento do lançamento do produto no mercado, contudo vindo a ser descoberto após a introdução no mercado e, causando danos ao consumidor, será responsabilizado o fornecedor, conforme previsto na legislação consumerista.
\end{abstract}

Imperioso salientar que, regra geral, a atividade médica tem natureza de obrigação de meio e não de resultado e, considerando a regra geral a responsabilidade deste profissional tem natureza subjetiva, em relação ao tratamento médico, nos termos do artigo $14 \S 4^{\mathrm{o}}$ do CDC.

Lado outro, o profissional médico enquanto operador ou até controlador responderá de forma objetiva em relação ao tratamento de dados do paciente. A fim de ilustrar podemos citar duas hipóteses que já são realidade, hodiernamente. Primeiro na qualidade de operador. Enquadra-se o profissional médico, fazendo uso da técnica da telemedicina e estando vinculado a qualquer plano de saúde realiza o tratamento de dados pessoais em favor deste, denominado como controlador.

Imagine-se ainda que o profissional médico pode ser enquadrado como controlador quando faz uso da técnica da telemedicina de forma autônoma ou até por meio do seu próprio consultório. Nessa hipótese compete a ele, diretamente, as tomadas das decisões referentes ao tratamento de dados pessoais dos seus pacientes. 
É importante frisar que a responsabilidade dos agentes de tratamento (controlador e operador) é solidária conforme prescrito no artigo 42 , $\S 1$, I e II. Cumpre esclarecer que as hipóteses de exclusão de responsabilidade estão previstas no artigo 43 da LGPD deixando de haver responsabilização quando os agentes de tratamento não realizarem o tratamento dos dados que lhes são atribuídos ou quando realizados não houver violação à legislação de proteção, ou ainda quando decorrer de culpa exclusiva do titular dos dados ou de terceiros.

Em relação à segurança dos dados informacionais havendo infringência da legislação, poderá acarretar multa de até $2 \%$ (dois por cento) incidente sobre o valor do faturamento da empresa, chegando até a monta de $R \$ 50.000 .000,00$ cinquenta milhões de reais, além de outras sanções previstas no artigo 52 da LGPD.

Quanto à segurança dos dados sejam eles sensíveis ou não, a principal limitação a ser enfrentada pela Saúde Suplementar no atendimento a LGPD diz respeito à ausência de uma política nacional única de segurança de dados de saúde, que influencia diretamente na relação desequilibrada com os consumidores.

\section{CONCLUSÃo}

Este estudo buscou introduzir reflexões sobre a natureza jurídica da responsabilidade civil do médico como agente de tratamento de dados, quando no exercício da telemedicina no âmbito privado, à luz da LGPD. Partindo da premissa de que este fenômeno será presente em nossa sociedade de consumo e da informação, buscou-se apontar limites e parâmetros para esta relação do direito e da tecnologia.

O estudo verificou que a técnica da telemedicina não é objeto de normatização por meio de Lei Ordinária, para além do período da pandemia do COVID-19. Assim, necessária a sua normatização, inclusive através de normas secundárias oriundas de agências reguladoras, no caso, da Agência Nacional de Saúde e da Autoridade Nacional de Proteção de Dados Pessoais, assim como já autorizado pelo Congresso Nacional, poderá o CFM regulamentá-la.

Espera-se que a regulamentação ocorra de forma aberta, livre e indiscriminada, de maneira que sejam convocados membros da comunidade acadêmica, representantes da sociedade civil, juristas, médicos especialistas entre outras pessoas que dominem a matéria. $\mathrm{O}$ debate sempre contribui para melhor racionalizar a regulamentação da norma, de modo que a os atos normativos que vierem a regulamentar a telemedicina no Brasil devem observar os princípios gerais do Código de Defesa do Consumidor, da Lei Geral de Proteção de Dados, sobretudo os direitos fundamentais dos cidadãos.

Um dos principais pontos que devem ser tratados com maior acuidade é a natureza da responsabilidade civil do profissional médico quando realiza o tratamento dos dados à luz da LGPD. Como visto, existe significativa divergência na doutrina sendo debatidas nesse estudo três correntes, a saber: (i) responsabilidade civil subjetiva; (ii) responsabilidade civil objetiva; (iii) responsabilidade civil proativa. 
O estudo concluiu que a responsabilidade civil do médico enquanto controlador e/ou operador do tratamento de dados goza de natureza objetiva, o que se extrai da interpretação da redação do artigo 42 da LGPD, haja vista a vinculação da responsabilidade do agente ao risco da sua atividade, remetendo aos ditames do artigo 927, § único do Código Civil.

Com efeito, os dados sensíveis estão intrinsicamente ligados aos direitos da personalidade dos cidadãos, porquanto devem ser criados mecanismos para conferir a maior proteção possível e responsabilização dos agentes de tratamento. Assim, preservados os dados pessoais, principalmente os dados sensíveis, estarão preservados os direitos da personalidade, bem como os direitos fundamentais naquilo que forem compatíveis.

\section{REFERÊNCIAS}

A nova realidade da telemedicina. Globo, Rio de Janeiro, 11 set. de 2020. Disponível em: <https://gente.globo.com/a-nova-realidade-da-telemedicina/>. Acesso em: 15 jan. de 2021.

Apesar de críticas, telemedicina já é realidade no país e deve se expandir. ABRAMGE, 2019. Disponível em: https://www.abramge.com.br/portal/index.php/pt-BR/abramge-na-midia/985apesar-de-criticas-telemedicina-ja-e-realidade-no-pais-e-deve-se-expandir. Acesso em 15 jan 2021.

BRASIL. Agência Nacional de Saúde Suplementar. ANEXO, I. ROL DE PROCEDIMENTOS E EVENTOS EM SAÚDE. Disponível em: https://www.unimedvtrp.com.br/wp-content/uploads/2020/09/Rol-de-Proc-eEventos-em-Sa\%C3\%BAde-2018-Anexos-I-II-III-e-IV.pdf. Acesso em 15 jan 2021.

. Agência Nacional de Saúde Suplementar. Nota Técnica noํ 06/2020. Dispõe sobre Adoção de medidas extraordinárias no âmbito da ANS para contenção da disseminação do covid-19. Disponível em:

https://www.ans.gov.br/images/stories/noticias/pdf/covid_19/nota-tecnica-6dirad-difis.pdf. Acesso em 15 jan 2021.

Câmara dos Deputados. Regimento interno, 2019. Disponível em: https://www2.camara.leg.br/atividade-legislativa/legislacao/regimento-internoda-camara-dos-deputados. Acesso em 15 jan 2021.

Constituição da República Federativa do Brasil de 1988. Disponível em: http://www.planalto.gov.br/ccivil_03/constituicao/constituicao.htm. Acesso em 15 jan 2021. 
. Poder Executivo. Lei n. 13.989 de 15 de abril de 2020. Dispõe sobre o uso da telemedicina durante a crise causada pelo coronavírus. Disponível em: http://www.planalto.gov.br/CCIVIL_03/_Ato2019-

2022/2020/Lei/L13989.htm\#: :text=1\%C2\%BA\%20Esta\%20Lei\%20autoriza\%20o,SA RS\%2DCoV\%2D2).\&text=3\%C2\%BA\%20Entende\%2Dse\%20por\%20telemedicina,1 es\%C3\%B5es \%20e\%20promo\%C3\%A7\%C3\%A3o\%20de\%20sa\%C3\%BAde.

Acesso em: 29 de dez. de 2020.

Poder Executivo. Lei n. 8.078 de 11 de setembro de 1990. Dispõe sobre o código de defesa do consumidor e dá outras providências. Disponível em: http://www.planalto.gov.br/ccivil_03/leis/18078compilado.htm. Acesso em 15 jan 2021.

Poder Executivo. Lei n. 12.965 de 23 de abril de 2014. Estabelece princípios, garantias, direitos e deveres para o uso da Internet no Brasil. Disponível em: http://www.planalto.gov.br/ccivil_03/_ato20112014/2014/lei/112965.htm. Acesso em 15 jan 2021.

Poder Executivo. Lei n. 13.709 de 14 de agosto de 2018. Dispõe sobre a Lei Geral de Proteção de Dados (LGPD). Disponível em: http://www.planalto.gov.br/ccivil_03/_ato2015-2018/2018/lei/L13709.htm. Acesso em 15 jan 2021.

Ministério da Saúde. Portaria MS no 467, de 20 de março de 2020. Dispõe, em caráter excepcional e temporário, sobre as ações de Telemedicina, com o objetivo de regulamentar e operacionalizar as medidas de enfrentamento da emergência de saúde pública de importância internacional previstas no artigo $3^{\text {o }}$ da Lei no 13.979, de 6 de fevereiro de 2020, decorrente da epidemia de COVID19. Diário Oficial da União, 2020.

Câmara dos Deputados. Projeto de Lei nº 1998/2020. Autoriza e define a prática da telemedicina em todo o território nacional. Disponível em: < https://www.camara.leg.br/propostas-legislativas/2249925>. Acesso em: 07 jan. 2021.

Câmara dos Deputados. Projeto de Lei no 2394/2020. Autoriza, aos profissionais da área da saúde, o exercício da profissão à distância por meio de tecnologias, na forma que especifica. Disponível em: < https://www.camara.leg.br/propostas-legislativas/2251583>. Acesso em: 07 jan. 2021.

COLUSSI, Fernando Augusto Melo; DOS SANTOS, Tomlyta Luz Velasquez. Novastecnologias e liberdade de expressão na pesquisa científica: Uma análise 
sobre a proteção de dados genéticos e de saúde. Revista de biodireito e direito dos animais, [s. 1.], v. 4, n. 2, p. 1-21, 2018. Disponível em:

http://search.ebscohost.com/login.aspx?direct=true\&db=afh\&AN=134656935\&lang =pt-br\&site=ehost-live. Acesso em: 8 set.2019.

CONSELHO FEDERAL DE MEDICINA. Resolução nº 1.643/2002. Define e disciplina a prestação de serviços através da Telemedicina. Conselho Federal de Medicina. Disponível em: https://sistemas. cfm. org. br/normas/visualizar/resolucoes/BR/2002/1643. Acesso em 15 jan 2021.

Ofício no 1756/2020 - COJUR. Brasília. Disponível em:

http://portal.cfm.org.br/images/PDF/2020_oficio_telemedicina.pdf. Acesso em 15 jan 2021.

. Resolução n⿳0 2.217/2018. Dispõe sobre o Código de Ética Médica.

Disponível em: https://portal.cfm.org.br/images/PDF/cem2019.pdf. Acesso em 15 jan 2021.

COSTA, José Augusto Fontoura et al. Telemedicina e uberização da saúde: médicos operários ou consumidores? CADERNOS IBERO-AMERICANOS DE DIREITO SANITÁRIO, v. 9, n. 3, p. 72-88, 2020.

FERRER-ROCA, Olga; SOSA-IUDICISSA, Marcelo. Handbook of Telemedicine. Third printing, 2002. Amisterdam: IOS Press, 1998. ISBN 9051994133.

GUEDES, Gisela Sampaio da Cruz; MEIRELES, Rose Melo Vencelau, Término do tratamento de dados, IN: Tepedino, Gustavo; Frazão, Ana; Oliva, Milena Donato. Lei Geral de Proteção de Dados Pessoais, Editora RT: São Paulo, 2019.

LUZ, Pedro Henrique Machado da; LOUREIRO, Maria Fernanda Battaglin. Privacidade e proteção de dados pessoais: Os novos desafios na sociedade em rede. Meritum: Revista de Direito da Universidade FUMEC, [s. 1.], v. 13, n. 1, p. 69-86, 2018. Disponível em:

http://www.fumec.br/revistas/meritum/article/view/5811/pdf. Acesso em: 14 set. 2019.

MARTINS, Guilherme Magalhães. O Direito ao Esquecimento na Internet. In: Direito Digital: direito privado e internet. 2. ed. São Paulo: Foco, 2019. p. 67.

MARTINS, Plínio Lacerda; FRANCO, Paulo Fernando; RAMADA, Paula Cristiane Pinto. A RELAÇÃO JURÍDICA DE CONSUMO E A VULNERABILIDADE DA PROTEÇÃO DOS DADOS PESSOAIS. In MARTINS, 
Plinio Lacerda: MARTINS, Guilherme Magalhaes: LIMA, Marcos Cesar de Souza. Hermenêutica Jurídica: A Relação de consumo na Sociedade. UFF. Niterói. 2019.

MENDES, Laura Schertel; DONEDA, D. . Comentário à nova Lei de Proteção de Dados (Lei 13.709/2018), o novo paradigma da proteção de dados no Brasil. REVISTA DE DIREITO DO CONSUMIDOR, v. 120, 2018.

MORAES, Maria Celina Bodin de; QUEIROZ, João Quinelato de. Autodeterminação informativa e responsabilização proativa: novos instrumentos de tutela da pessoa humana na LGDP. IN: Cadernos Adenauer, volume 3, Ano XX, 2019.

NUNES JUNIOR, Vidal Serrano; DALLARI, Sueli Gandolfi. Direito Sanitário. São Paulo: Verbatim, 2010.

PEREIRA, Paula Moura Francesconi Lemos. O uso da Internet na prestação de serviços médicos. In: MARTINS, Guilherme Magalhães; LONGHI, João Victor Rozatti(coord.) Direito Digital; Direito privado e Internet. 3.ed. Indaiatuba: Foco, 2020.

RESOLUÇÃO, CFM. nº 1.643/2002. Define e disciplina a prestação de serviços através da Telemedicina. Conselho Federal de Medicina. Disponível em: https://sistemas. cfm. org. br/normas/visualizar/resolucoes/BR/2002/1643. Acesso em 15 jan 2020.

RESENDE, N. F. A amplitude da expressão saúde no marco normativo brasileiro. Direito à vida e à saúde: impactos orçamentários e judicial. São Paulo: Atlas, 2010.

TOSTES, Eduardo Chow De Martino. Saúde Suplementar: Reajuste de Planos de Saúde Coletivos. Rio de Janeiro. Lumen Juris, 2019.

TOSTES, E. C. M.; ALVISI, E.; Martins, Plínio Lacerda. Saúde suplementar considerações e críticas sobre a regulação da ANS e a tutela coletiva dos direitos. In: Kátia Junqueira. (Org.). Repensando a regulação no Brasil novas visões e propostas. 1ed.Rio de Janeiro: Synergia Editora, 2019, v. 1, p. 193-317. 